\title{
Knowledge, Attitudes and Practices of Women in the Southern Region of Saudi Arabia Regarding Cervical Cancer and the Pap Smear Test
}

\author{
Enas A Dhaher*
}

\begin{abstract}
Background: The main barrier for women to receive Papanicolaou (Pap) smear tests and immunization is lack of knowledge about the disease's signs and symptoms, women's attitudes toward prevention programs and cultural myths and beliefs. Therefore, the main objective of this study is to measure women's knowledge, attitudes and practices about cervical cancer and the Pap smear test in the southern region of Saudi Arabia and to assess the findings in relation with women's demographics. Methods: A cross sectional survey was conducted at the Armed Forces Hospital Southern Region Obstetrics and Gynecology Clinic using a self-administered questionnaire with a sample size of 255 women between the ages of 15 and 65 years. Results: Forty-three percent of the women in this region are aware of cervical cancer, but do not recognize its risk factors, implications, timing or main cause, which is Human papillomavirus (HPV). In fact, the primary source of information was obtained through social media. Only two women conducted Pap smear test and that was based on doctor's referral, where women's main reason from not conducting the test was feeling good and no need. Conclusions: There is a need, therefore, to create awareness programs for cervical cancer, its causes and risk factors, as well as its preventive measures for women in the southern region of Saudi Arabia.
\end{abstract}

Keywords: Cervical cancer- Pap-smear test- knowledge- Saudi Arabia

Asian Pac J Cancer Prev, 20 (4), 1177-1184

\section{Introduction}

Cervical cancer is the second most common cancer among women worldwide at a yearly death rate of 274,$000 ; 88 \%$ of these cases were reported in developing countries (WHO, 2008). According to the World Health Organization (WHO, 2013) cervical cancer is highly curable, therefore, the main culprits for high mortality rates were lack of effective prevention, early detection and treatment programs, and access to available preventive programs . Epidemiological studies found that cervical cancer was highly correlated to Human papillomavirus (HPV) after controlling for other risk factors (Ferlay et al., 2015; Al Zaabie et al., 2015).

Several risk factors were studied worldwide to find that smoking, sexual relationships with multiple partners, multiple marriages, and dietary habits were leading in cervical cancer diagnoses (Hosono et al., 2010; Basu et al., 2014; Patel et al., 2018; Sharma and Pattanshely, 2018). Early marriage and childbirth and multiple pregnancies were also found to be high risk for cervical cancer (Basu et al., 2014). Muradi et al., (2017) stated that vaginal inflammation was a high risk factor for developing cervical cancer, as chronic infection could develop into cervical dysplasia and cervical cancer, in addition to poor hygiene and low socioeconomic status (Velenciuc, 2009).

Since the time of introducing the conventional Pap smear test and early detection programs, mortality rates have shown dramatic decreases in developing countries by $70 \%$ (Salslow et al., 2002). Reports from developing countries showed that the main barriers to receiving Pap smear tests were lack of overall knowledge about the disease, its signs and symptoms, the importance of prevention and the preventive measures, women's attitudes towards the preventive measures for cervical cancer, and general myths and beliefs (Nwankwo et al., 2011; Esin et al., 2011; Reisetal, 2012). The American College of Obstetricians and Gynecologists (ACOG) urged women who had been or were still sexually active, and those at least 21-years of age to have an annual Pap smear test and pelvic examination. For those 30 years and above who have had three successive normal pelvic examinations and Pap smear tests, the ACOG advised for monitoring on longer intervals (Ozan, 2005)

According to Saudi Arabia's cancer statistics, of the 152 cervical cancer cases detected yearly, 55 die with a 1.3 incident rate (Addar, 2017). According to Alsbeih (2014) in Saudi Arabia cervical cancer placed at the

Dean of the Female Nursing Institute, Armed Forces Hospital Southern Region of Saudi Arabia. *For Correspondence: enasassaf2015@gmail.com 
eighth common cancer among women in the age group 14 to 44. There were some studies conducted for HPV detection; 100 women were tested in Jeddah at King Fahad University Hospital resulted in a $94 \%$ negative rate for HPV (Gazzaz, 2007). Another study of volunteer, cervical cytology screening was conducted in the western region of the Kingdom with 485 women at King Abdulaziz University Hospital. Only 5.6\% were found to be high-risk HPV (60 years and above), and 188 women from the 40-49 age group were found more likely to accept HPV testing (Bondagji et al, 2013). While a study in Riyadh revealed that $31.6 \%$ of 120 women had HPV $16 / 18$, and 10 had cervical abnormality out of which six were positive HPV 16/18 (Al-Muammar et al., 2007). Al Sheikh's (2014) study found that the HPV prevalence in the Saudi native population was still unknown.

One recent study conducted in Riydh by Jaradi and Bwazir (2019) assessing women's knowledge, attitudes and practices towards cervical cancer through focus group discussion with 77 women revealed that women were lacking knowledge regarding cervical cancer and pap smear test neither immunization, and screening was not necessary since they do not complain of any diseases.

The main objective of this study is to measure women's knowledge, attitudes and practices of cervical cancer and its preventive measures in the southern region of Saudi Arabia.

\section{Materials and Methods}

\section{Study design}

A cross-sectional survey of 255 Saudi women of at least 15 years of age was conducted at the Obstetrics and Gynecology Outpatient Clinic of the Armed Forces Hospitals Southern Region (AFHSR) in Saudi Arabia regardless of the visit reason. The study was conducted between March and April 2017. The clinic was selected, as it provided reproductive health care services to the entire southern region of Saudi Arabia, which included antenatal care, high-risk pregnancy, gynecology, infertility treatment, postnatal care, and family planning. Furthermore, the clinic was connected to the Obstetrics and Gynecology of the hospital where, on average, about 370 patients receive care daily.

\section{Study instrument}

Based on literature review self-administered questionnaire was developed, it consists of two main parts demography (15 questions) and knowledge, attitudes and practices of cervical cancer and the HPV vaccine. (15 questions). All questions were formulated in a simple direct language and the answers were given in a list of options where women supposed to choose one option only, an option was provided for the knowledge question which is" I don't know ". The questionnaire was pilot tested (test-retest) with 25 women whom were not included in the study. The questionnaire was reliable with person's correlation of 0.80 . The alpha value for the overall questionnaire was 0.90 .

\section{Sample and data collection}

Sample size: The sample was designed assuming the total population visiting the clinic in one month was 8000 women based on clinic statistics and appointments. A sample of 250 women with a confidence level of $95 \%$ will provide $50 \%$ of women answering the questions of the entire relevant population with a $50 \pm 6.1$ confidence interval and $80 \%$ power to check for differences. Given the excellent response rate, the questionnaire was distributed to 275 women, and 255 questionnaires were returned with a response rate of $93 \%$.

Data was collected daily for one month. Questionnaires with additional health education materials (healthy life style and nutritional habits) or educational materials without questionnaires were distributed in sealed envelopes to ensure randomization to all the women (simple randomization was done in that every other woman in the waiting area received a questionnaire that accounts around $50 \%$ of the attending women receive the questionnaire at the time of data collection). Women with at least 15 years of age, and all present in the clinic regardless of their reason for attendance (a client or a companion) were the target subject of the study. The researcher was available to assist illiterate women and those with questions regarding the purposes of the study.

\section{Ethical consideration}

This study was approved by the Research Ethical Committee at the Armed Forces Hospital in the Southern Region, prior to the research being conducted and furthermore, consent forms were signed by all participants in the research where it included the purpose of the study and ensure anonymity and privacy.

\section{Statistical analysis}

The Predictive Analytics SoftWare 18 (PASW) was used to enter and analyze the data. Frequency distributions were used to present women's demographic characteristics, knowledge, attitudes and practices related to cervical cancer and the Pap smear test. Cross tabulations were used to assess the demographic factor relations regarding the same.

\section{Results}

Sample demographic and obstetric characteristics

The mean age of women was 32 years, with the majority above 25 years. Approximately $11 \%$ of the women were illiterate, and $32 \%$ were university graduates. The educational levels of the husbands were half-attained secondary schooling, and 19\% were diploma and university degree holders. Among the women's professional careers, $2.7 \%$ were in health professions and $19 \%$ were teachers and educators. Overall, only $15 \%$ of the women participating in the study were currently employed (Table 1).

Women's obstetric and marital characteristics revealed half were married for more than 10 years, and the majority had four pregnancies. The median and mean number of deliveries was 2.95 and 2.80 respectively. When excluding women with no children, the mean number of children 
Table 1. Women's Sociodemographic Characteristics $(\mathrm{n}=255)$

\begin{tabular}{|c|c|}
\hline Characteristics & $\mathrm{n}(\%)$ \\
\hline \multicolumn{2}{|l|}{ Women's age group } \\
\hline $16-20$ & $9(3.5)$ \\
\hline $21-25$ & $39(15.3)$ \\
\hline $26-30$ & $75(29.4)$ \\
\hline $31-35$ & $57(22.4)$ \\
\hline Above 35 & $76(29.4)$ \\
\hline \multicolumn{2}{|c|}{ Mean:32 } \\
\hline \multicolumn{2}{|c|}{ Women's level of education } \\
\hline Never went to school & $27(10.7 \%)$ \\
\hline Basic schooling & $41(16.1)$ \\
\hline Secondary Schooling & $92(36.1)$ \\
\hline Diploma & $13(5.1)$ \\
\hline University & $82(32.2)$ \\
\hline \multicolumn{2}{|l|}{ Husband Educational level } \\
\hline Never went to school & $30(11.8)$ \\
\hline Basic schooling & $26(10.2)$ \\
\hline Secondary Schooling & $133(52.2)$ \\
\hline Diploma & $10(3.9)$ \\
\hline University & $49(15.3)$ \\
\hline \multicolumn{2}{|c|}{ Women's professional career } \\
\hline None & $160(62.7)$ \\
\hline Health & $7(2.7)$ \\
\hline Admin & $19(7.5)$ \\
\hline Profession & $20(7.8)$ \\
\hline Academic & $49(19.2)$ \\
\hline \multicolumn{2}{|c|}{ Husband professional career } \\
\hline None & $188(73.7)$ \\
\hline Health & $10(3.9)$ \\
\hline Admin & $13(5.1)$ \\
\hline Profession & $23(9.0)$ \\
\hline Academic & $21(8.2)$ \\
\hline \multicolumn{2}{|l|}{ Women's working stats } \\
\hline Yes & $38(14.9)$ \\
\hline No & $217(85.1)$ \\
\hline
\end{tabular}

increased to 3.57. Nine percent of women reported having more than six living children, and nearly half of the women had never used family planning methods. Interestingly, only $23 \%$ of women had ever conducted a comprehensive reproductive health assessment (Table 2).

Women's knowledge, attitudes and practices of cervical cancer and Pap smear test.

While close to three quarters of the women had ever heard of cervical cancer, the primary source of information was from social media, mainly Facebook and Twitter. Responding to further questions related to the risk factors of cervical cancer, around two thirds of women responded with either do not know or not a risk factor. More than half of the women recognized vaginal inflammation as a risk
Table 2. Marital, Obstetric and Gynecologic History of Study Population $(\mathrm{n}=255)$

\begin{tabular}{lc}
\hline Characteristic & $\mathrm{n}(\%)$ \\
\hline Marriage years & $5(2.0)$ \\
Single & $129(50.6)$ \\
Less than 10 year & $121(47.5)$ \\
10 years and more & median=10.72 years \\
& \\
No. of pregnancies & $18(7.1)$ \\
0 & $120(47.1)$ \\
1-3 & $74(29.0)$ \\
$4-6$ & $43(16.9)$ \\
More than 6 & median=3.89 \\
& \\
No. of deliveries & $51(20.0)$ \\
0 & $124(48.6)$ \\
1-3 & $55(21.6)$ \\
4-6 & $25(9.8)$ \\
More than 6 & median=2.95 \\
No. of living children & \\
0 & $58(22.7)$ \\
1-3 & $197(77.3)$ \\
Mer 6 & $55(21.6)$ \\
More than 6 & $123(48.2)$ \\
\hline
\end{tabular}

factor, but almost none knew the direct cause of cervical cancer. Regarding attitudes of prevention, approximately $57 \%$ responded that cervical cancer (HPV) could be prevented, only two women had ever conducted Papsmear test based on doctors referral but close to all women had never heard of the HPV vaccine and, consequently, only one woman had received the vaccination in the United States. A new variable was created with the total number of risk factor recognized by women in four categories $(0$; $1-2 ; 3-4 ;>4)$ to find out that the highest percentage was with those recognize no risk factors (Table 3 ).

Number of risk factors was highly significant $(p=0.001)$ with women's level of education as those with higher education recognize more risk factors. Whereas none of the demographic factors was correlated with number of risks recognized neither the availability of cervical cancer immunization.

Regarding the Pap smear test, $43 \%$ of women had ever heard of the test through various media channels, $32 \%$ had received health and wellness information from female medical professionals, approximately $64 \%$ were 
Table 3. Women's Knowledge, Attitudes and Practices of Cervical Cancer $(\mathrm{n}=255)$

\begin{tabular}{lc}
\hline Characteristics & $\mathrm{n}(\%)$ \\
\hline Ever heard of cervical cancer & \\
Yes & $169(66.3)$ \\
No & $86(33.7)$ \\
Sources of information & \\
Family/friends & $22(13.0)$ \\
Family doctor/GP & $2(1.2)$ \\
OBGYN doctor & $11(6.5)$ \\
Nurse & $1(0.6)$ \\
Media & $133(78.7)$
\end{tabular}

Knowledge about risk factors for cervical cancer

1.Early marriage

$\begin{array}{lr}\text { Yes } & 49(19.2) \\ \text { no } & 50(19.6) \\ \text { Don't know } & 156(61.2)\end{array}$

2.Marrying more than one husband during reproductive age Yes

No

Don't know

$176(69.1)$

3.Close multiple pregnancies

Yes

$49(19.2)$

No

$50(19.6)$

Don’t know

$156(61.2)$

4.Smoking

Yes

No

Don't know

$135(52.9)$

5.Nutritional habits

Yes

No

Don't know

$145(56.9)$

6.Too many children

Yes

$44(17.3)$

No

$62(24.3)$

Don’t know

$149(58.4)$

7.Poor hygiene

Yes

$108(42.4)$

No

Don’t know

$130(51.0)$

8.Low socioeconomic level

Yes $46(18.0)$

No $\quad 50(19.6)$

Don't know

$159(62.4)$

9.Vaginal inflammation

Yes

$134(52.5)$

$3(1.2)$

No

$118(46.3)$
Table 3. Continued

\begin{tabular}{lc}
\hline Characteristics & $\mathrm{n}(\%)$ \\
\hline Number of risk factors recognized & \\
0 & $87(34.1)$ \\
$1-2$ & $59(23.1)$ \\
$3-4$ & $58(22.7)$ \\
$>4$ & $51(20.0)$ \\
Direct cause of the cervical cancer & \\
HIV & $1(0.4)$ \\
HPV & $0(0.0)$ \\
Chlamydia & $1(0.4)$ \\
Don't know & $253(99.2)$ \\
Cervical cancer can be prevented & \\
Yes & $142(55.7)$ \\
No & $5(2.0)$ \\
Don't know & $108(42.4)$ \\
Ever Heard of vaccine for cervical Cancer $(\mathrm{HPV})$ \\
Yes & $10(3.9)$ \\
No & $7(2.7)$ \\
Don't know & $238(93.3)$ \\
Have you ever took the vaccine & $1(0.4)$ \\
Yes & $254(99.6)$ \\
No &
\end{tabular}

unaware that the test could discover asymptomatic lesions, and $56 \%$ recognized that early detection could lead to better outcomes. Regarding attitudes towards the test, only $38 \%$ of women said they would participate in a screening if they were properly informed. The reasons mentioned for those not willing to participate ranged most from no complaints to least husband disagreement, $45.5 \%$ and $2.6 \%$ respectively. Two third of those willing to participate in the screening preferred served by a female gynecologist at an OB/GYN hospital (Table 4).

The relationship between women's characteristics and their KAP towards Cervical cancer and Pap smear test.

Based on cross tabulation a significant relationship was found between women's level of education and knowledge about cervical cancer $(\mathrm{P}=0.000)$. In addition, Women of higher education levels showed significant acceptance of participation in screening tests when properly informed $(\mathrm{P}=0.009)$. Significant relationship was found between the belief that cervical cancer can be prevented with educational level $(\mathrm{P}=0.010)$.

Those with medical professions or those with any other professional careers were more knowledgeable about the disease than other areas. Number of deliveries showed a significant relationship between women's knowledge of both cervical cancer and the Pap smear test $(\mathrm{P}=0.029$ and $\mathrm{P}=0.041)$. None of the other demographic characteristics showed a significant relationship between women's knowledge, attitudes and practices.(Table 5).

\section{Discussion}

In the southern region of Saudi Arabia, there were no 
Table 4. Women's Knowledge, Attitudes and Practices of Pap Smear Test $(\mathrm{n}=255)$

\begin{tabular}{lc}
\hline Characteristics & $\mathrm{n}(\%)$ \\
\hline Have you heard of pap smear test & $111(43.5)$ \\
Yes & $144(56.5)$ \\
No & \\
Sources of information & $8(7.2)$ \\
Family/friends & $2(1.8)$ \\
Family doctor/GP & $31(27.9)$ \\
OBGYN doctor & $3(2.7)$ \\
Nurse & $67(60.4)$ \\
Media & $93(36.5)$ \\
Pap smear can identify early asymptomatic lesions \\
Yes & $8(3.1)$ \\
No & $154(60.4)$ \\
Don't know &
\end{tabular}

Early detection of cervical cancer has good effect on outcome of treatment

$\begin{array}{lc}\text { Yes } & 142(55.7) \\ \text { No } & 5(2.0) \\ \text { Don't know } & 108(42.4)\end{array}$

If properly informed about Pap smear would you do it?

Yes

No

Don't know

$80(31.4)$

If refuses to do Pap Smear, what are the causes?

May be painful

I feel shy

I am healthy, no need

Husband would not agree

Physician doesn't request

Don not know where to go

$40(25.6)$

If you agree to do Pap Smear, whom do u prefer to do it?

Family doctor

OBGYN

Private doctor

Mother and child health doctor

nurse

If you agree to do Pap smear, what is the preferred health provider gender?

Male

Female

If you agree to do Pap smear, where is the preferred place?

Women clinic in hospital

Obs. and Gyne in hospital

Private clinic

$11(11.1)$

screening programs or public educational campaigns for cervical cancer and its prevention at the time of this study. This study demonstrated that while close to two third of women recognize cervical cancer, few knew of its risk factors and almost none knew of the direct cause, which represents the studied women having less knowledge than participants in the Jeddah study and Kuwait (Sait, 2009; Al Sairafi and Mohamed , 2009 ). Previous studies found that lack of knowledge regarding risk factors of cervical cancer might be the most important factor for women not obtaining screening tests (Were et al., 2011; Aswathy et al., 2012; Nadarzynski et al., 2012). The lack of national screening programs and public education campaigns could explain why women were not aware of the disease's risk factors.

Regarding the Pap smear test, less than half the women were aware of it and about two thirds had no knowledge of the purpose of the test, which, again, represents a stark contrast to the Jeddah study (Sait, 2009). Additionally, half of the women thought early detection could lead to better outcomes.

Our study showed the majority of women's source of information regarding both cervical cancer and the Pap smear test was from social media, which is considered the most popular form of communication, including the communication of health information. Eight out of 10 internet users seek health information online, and two thirds seek social media to access health information in the United States (Child and Martin, 2012; Von Muhlen and Ohno-Machada, 2012). Social media could help improve and promote healthy communities when used properly (Ventola, 2014), increase access to educational health resources, and even track personal health progress (Lambert et al., 2012; Mac Millan, 2013; Grindrod et al., 2014). However, use of social media as the main source of health information could be dangerous in terms of content reliability and accuracy, currency, affiliation and authority (Moorhead et al., 2013; Pirraglia and Kravitz, 2012). Eventually in this study, we found that women recognized cervical cancer and the Pap smear, but were not familiar with risk factors or preventive measures. Despite the dangers of social media, it could be used as an effective educational tool in the southern region of Saudi Arabia. Well-organized media campaigns featuring famous regional figures or movie stars could be beneficial. Hyacinth et al., (2012) suggested a similar recommendation with the dissemination of information regarding knowledge and awareness of cervical cancer and the Pap smear test.

Level of education and type profession were found to be highly correlated to women's knowledge about cervical cancer and the Pap smear test, as well as their attitudes toward preventing cervical cancer. Level of education was found to be a positive factor in other studies in Saudi Arabia and Kuwait (Amarin et al., 2008; Ravichandren et al., 2011).

Regarding attitudes toward preventive Pap Smear tests, more than half of the women agreed that early detection could prevent cervical cancer, and 38\% agreed to participate in a screening program similar to the Akanb et al., (2015) and Almobarak et al., (2016) studies.

The main barrier for not getting the Pap smear test was having no complaints, which could be explained by lack of knowledge regarding the disease and prevention, as discussed above. Moreover, if women had no symptoms 
Table 5. The Relationship between Women's Selected Characteristics and Women's Knowledge, Attitudes, and Practices of Cervical Cancer and Cervical Cancer Prevention $(\mathrm{n}=255)$

\begin{tabular}{|c|c|c|c|c|}
\hline Characteristics (n) & $\begin{array}{l}\text { Knowledge } \\
\mathrm{CCa}\end{array}$ & $\begin{array}{l}\text { Knowledge } \\
\text { Pap Smear }\end{array}$ & $\begin{array}{l}\text { When properly informed about Pap } \\
\text { smear, women would do it. }\end{array}$ & $\begin{array}{l}\mathrm{CC} \text { can be } \\
\text { prevented }\end{array}$ \\
\hline \multicolumn{5}{|l|}{ Women's level of education } \\
\hline Never went to school (27) & $9(33.3)$ & 7 (25.9) & $9(33.3)$ & $6(22.2)$ \\
\hline Basic schooling (41) & $23(56.1)$ & $15(36.6)$ & $10(24.4)$ & $19(46.3)$ \\
\hline Secondary schooling (92) & $64(69.6)$ & $39(42.2)$ & $30(32.6)$ & $53(57.6)$ \\
\hline Diploma (13) & $6(46.2)$ & $7(53.8)$ & $9(69.2)$ & $9(69.2)$ \\
\hline \multirow[t]{2}{*}{ University (82) } & $67(81.7)$ & $43(52.4)$ & $41(50.0)$ & $55(67.1)$ \\
\hline & $\mathrm{P}=0.000^{*}$ & $\mathrm{P}=0.113$ & $\mathrm{P}=0.009^{*}$ & $\mathrm{P}=0.010^{*}$ \\
\hline \multicolumn{5}{|l|}{ Women's area of specialty } \\
\hline Medical (7) & $6(85.7)$ & $6(85.7)$ & $5(71.4)$ & $7(100.0)$ \\
\hline Admin (19) & $16(84.2)$ & $12(63.2)$ & $9(47.4)$ & $11(57.9)$ \\
\hline Profession (23) & $13(65.0)$ & $12(60.0)$ & $14(70.0)$ & $15(75.0)$ \\
\hline \multirow[t]{2}{*}{ Academic (21) } & $38(77.6)$ & $21(42.9)$ & $23(46.9)$ & $31(63.3)$ \\
\hline & $\mathrm{P}=0.049^{*}$ & $\mathrm{P}=0.013^{*}$ & $\mathrm{P}=0.007^{*}$ & $\mathrm{P}=0.005^{*}$ \\
\hline \multicolumn{5}{|l|}{ No. of deliveries } \\
\hline $0(51)$ & $30(58.8)$ & $16(31.4)$ & $21(41.2)$ & $31(60.8)$ \\
\hline $1-3(124)$ & $89(71.8)$ & $59(47.6)$ & $51(41.1)$ & $70(56.5)$ \\
\hline $4-6(55)$ & $39(70.9)$ & $9(52.7)$ & $20(36.4)$ & $34(61.8)$ \\
\hline \multirow[t]{2}{*}{7 and more (25) } & $11(44.0)$ & $7(28.0)$ & $7(20.0)$ & $7(28.0)$ \\
\hline & $\mathrm{P}=0.029^{*}$ & $\mathrm{P}=0.041 *$ & $\mathrm{P}=0.780$ & $\mathrm{P}=0.050^{*}$ \\
\hline
\end{tabular}

a, Cervical Cancer; ${ }^{*}$, significant at $\mathrm{p}<0.05$

and did not feel sick, it was assumed that diagnostic procedures like the Pap smear test were unnecessary, the study in Riyadh supports the same result (Jaradi and Bawazir, 2019). Similar beliefs were found in studies in Indonesia, Qatar and Iran (Wong et al., 2008; Al-Ali et al., 2016; Ashtarian et al., 2017 respectively). Fear of pain and embarrassment, which could be considered a misconception of the test, were barriers found in studies in Malaysia and Ghana (Wong et al., 2008; Ebu, et al., 2015 respectively).

Another barrier mentioned by the women, no information about where to go (26.6\%), considered a very important and devastating barrier, as found in the Ghana study (Ebu et al., 2015). Other barrier as waiting for the physician to recommend the Pap smear test was found in the Kuwait and Jeddah studies (Al Sairafi and Mohamed, 2009; Sait, 2009).

The aforementioned barriers could be explained as lack of awareness about cervical cancer and its prevention techniques, and lack of knowledge about the Pap smear test, and its implications and procedure. Several other studies posited the same (Asgharnia et al., 2009; Nwankwo et al., 2011; Farshbaf-Khalili et al., 2015). Our study showed that women with a higher level of education, and those with medical backgrounds or other professional careers were more likely willing to have Pap smear tests compared to those with less education, no education, or other educational backgrounds. This would support the thinking that awareness and knowledge played a significant role in women's attitudes. Medical backgrounds and high levels education were previously found to be significant with women's attitude of having the Pap smear test in a KAP study in The Sudan study (Almobarak et al., 2016). Conversely, among those who were willing to have the test in this study, 94\% preferred a female health care provider, which was also found in a Kuwait KAP study (Al Sairafi and Mohamed, 2009), and among older American women (Guilfoyle et al., 2007). The study also found that a high number of deliveries were significantly associated with more awareness regarding cervical cancer and the Pap smear test. Which could be related to frequent contact with a medical and health staff during the reproductive life span and more chance for health education or health related information to be given.

Alsbeih (2014) concluded that neither national screening programs nor national vaccination programs against the HPV virus would be cost-effective in reducing cervical cancer in Saudi Arabia, as the reported incidence was already low. While the same study discussed the real prevalence of HPV was not recorded among native women in Saudi Arabia, our study showed that women were lacking knowledge regarding the Pap smear test, and cervical cancer risk factors, implications, and methods of prevention. Despite the recommendation from Alsbeih, women should have the right to choose screening tests, in which case, information on preventive measures need to be available to all women. Freedom of choice could be accomplished when women are well-informed of the disease and its available preventive measures. Therefore, it's recommended in this study to organize a mass media campaign educating women about cervical cancer, the Pap smear test, and prevention measures targeted to women of the southern region of Saudi Arabia. 


\section{Funding Statement}

No funding source.

\section{Study strength and Limitations}

High response rate is considered one of the study strength, variation in between the sample is also a strength but since the study is taking place at the obstetric clinic social desirability bias might be significant here.

\section{Statement conflict of Interest}

No conflict of interest declared.

\section{Acknowledgements}

Would like to acknowledge the staff of the Obstetrics and Genecology out-patient clinics at the Armed Forces Hospital Southern region and the nurse-in-charge for facilitating the process of data collection.

\section{References}

Addar M (2017). Chairmen Gyneocology section. King Saud University. Cervical cancer and HOV vaccine Guidelines in Saudi Arabia lecture. Available at retrieved on 25th of Jan.2017: http://sgog.org/wp-content/PDF/Cervical\%20 Screening\%20and\%20HPV\%20Vaccine\%20Guidelines\%20 In $\% 20$ Saudi\%20Arabia.pdf.

Akanbi OA, Iyanda A, Osundare F, Opaleye OO (2015). Perceptions of Nigerian women about human Papilloma virus, cervical cancer, and HPV vaccine. Scientifica, 2015, 285702.

Al -Ali A, Salem M, El Mahdi A, et al (2016). Knowledge , attitudes and practices regarding cervical cancer screening among female health care workers in primary healthcare in Qatar. MEJFM, 14, issue8.

Almobarak AO, Elbadawi AA, Elmadhoun WM, Elhoweris MH, Ahmed MH (2006). Knowledge, attitudes and practices of Sudanese women regarding the Pap Smear test and cervical cancer. Asian Pac J Cancer Prev, 17, 625-30.

Al-Muammar T, Al-Ahdal MN, Hassan A, et al (2007). Human papilloma virus-16/18 cervical infection among women attending a family medical clinic in Riyadh. Ann Saudi Med, 27, 1-5.

Al Sairafi M, Mohamed FA (2014). Knowledge, attitudes, and practice related to cervical cancer screening among Kuwaiti women. Med Princ Pract, 18, 35-42.

Alsbeih G (2014). HPV infection in cervical and other cancers in Saudi Arabia: Implication for prevention and vaccination. Front Oncol, 4, 65.

Al sheikh, G (2014). HPV infection in cervical and other cancers in Saudi Arabia implication for prevention and vaccination. Front Oncol, 4, 65.

Al Zaabi M, Al Muqbali S, Al Sayadi T, et al (2015). Age specific cytological abnormalities in women screened for cervical cancer in the Emirate of Abu Dhabi. Asian Pac J Cancer Prev, 16, 6375-9.

Amarin, ZO, Badria LF, Obeidat BR (2008). Attitudes and beliefs about cervical smear testing in ever-married Jordanian women. East Mediterr Health J, 14, 389-97.

Ashtarian H, Mirzabeigi E, Mahmoodi E, Khezeli M (2017). Knowledge about cervical cancer and Pap Smear and the factors influencing the Pap test screening among women. Int J Community Based Nurs Midwifery, 5, 188-95.

Asgharnia M, Mirbolouk F, Oudi M, et al (2009). Frequency of pap smears test and attitude about it among post partum women referred to alzahra hospital in Rasht. J Health, 1, $57-65$.

Aswathy S, Quereshi MA, Kurian B, Leelamoni K (2012). Cervical cancer screening: current knowledge and practice among women in a rural population of Kerala, India. Indian J Med Res, 136, 205-10.

Basu P, Hasan S, Flieeshia F, et al (2014). Knowledge, attitude and practices of women in Maldives related to the risk factors, prevention and early detection of cervical cancer. Asian Pac J Cancer Prev, 15, 6691-5.

Bondagji NS, Gazzaz FS, Sait K, Abdullah L (2013). Prevalence of high-risk human papillomavirus infections in healthy Saudi women attending gynecologic clinics in the western region of Saudi Arabia. Ann Saudi Med, 33, 13-7.

Childs LM, Martin CY (2012). Social media profiles: striking the right balance. Am J Health System Pharm, 69, 2044-50.

Ebu NI, Muoeoi SC, Siakwa MP, Sampselle CM (2015). Knowledge, practice, and barriers toward cervical cancer screening in Elmina, Southern Ghana. Int J Womens Health, 7, 31-9.

Esin MN, Bulduk S, Ardic A (2011). Beliefs about cervical cancer screening among Turkish married women. J Cancer $E d u$, 26, 510-5.

Farshbaf-Khalili A, Salehi-Pourmehr H, Shahnazi M, et al (2015). Cervical cancer screening in women referred to healthcare centers in Tabriz, Iran. Niger Med J, 56, 28-34.

Ferlay J, Soerjomataram I, Dikshit R, et al (2015).Cancer incidence and mortality worldwide: sources, methods and major patterns in GLOBOCAN 2012. Int J Cancer, 136, $359-86$.

Gazzaz FB (2007). Molecular testing of human papilloma virus in cervical specimens. Saudi Med J, 28, 1810-8.

Guilfoyle Sh, Franco R, Gorin SS (2007). Exploring older women's approaches to cervical cancer screening. Health Care Women Int, 28, 930-50

Grindrod K, Forgione A, Tsuyui RT, et al (2014), Pharmacy 2.0: a scoping review of social media use in pharmacy. Res Social Adm Pharm, 10, 256-70.

Hosono S, Matsuo K, Kajiyama H, et al (2010). Association between dietary calcium and vitamin $\mathrm{D}$ intake and cervical carcinogenesis among Japanese women. Eur J Clin Nutr, 64, 400-9.

Hyacinth HI, Adekeye OA, Ibeh JN, Osoba T (2012). Cervical cancer and Pap Smear awareness and utilization of Pap Smear test among Federal Civil Servants in North Central Nigeria. PLoS One, 7, e46583.

Jradi H, Bawazi A (2019). Knowledge, attitudes, and practices among Saudi women regarding cervical cancer, human papillomavirus (HPV) and corresponding vaccine. Vaccine, 37, 530-7.

Lambert KM, Barry P, Stokes G /(2012). Risk management and legal issues with the use of social media in the healthcare setting. J Health Risk Manag, 31, 41-7.

Mac Millan C (2013). Social media revolution and blurring of professional boundaries. Imprint, 60, 44-6.

Moorhead SA, Hazlet DE, Harrison L, et al (2013). A new dimension of health care: systemic review of the uses, benefits, and limitations of social media for health care professionals. J Med Internet Res, $\mathbf{1}, \mathrm{e} 85$.

Moradi, S, Hasan MT, Darvish 1, Roozbeh N (2017). Evaluating Cervicovaginal Infections and Cervical Cancer in Women with Low Socioeconomic Levels. Iran J Public Health, 46, 867-8.

Nadarzynski T, Waller J, Robb KA, Marlow LA (2012).Perceived risk of cervical cancer among pre-screening age women (18-24 years): the impact of information about cervical cancer risk factors and the causal role of HPV. Sex Transm 
Infect, 88, 400-6.

Nwankwo KC, Aniebue UU, Aguwa EN, Anarado AN, Agunwah E (2011). Knowledge attitudes and practices of cervical cancer screening among urban and rural Nigerian women: a call for education and mass screening. Eur J Cancer Care, 20, 362-7.

Ozan H (2005). PAP Smear: When? How? Who?. Turk J Gynecol Obstet, 2, 35-40.

Patel A, Pathak T, Patel J, Sutariya V (2018). Role of nutritional factors in pathogenesis of cancer. Food Qual Safe, 2, 27-36.

Pirraglia PA, Kravitz RL (2012). Social media: new opportunities, new ethical concerns. J Gen Intern Med, 28, 165-6.

Ravichandrann K, Al-Hamdan NA, Mohamedn G (2011). Knowledge, attitude, and behavior among Saudis toward cancer preventive practice. J Family Community Med, 18, 135-42.

Reis N, Bebis H, Kose S, et al (2012). Knowledge, behavior and beliefs related to cervical cancer and screening among Turkish women. Asian Pac J Cancer Prev, 13, 1463-70.

Sait KH (2009). Attitudes, knowledge, and practices in relation to cervical cancer and its screening among women in Saudi Arabia. Saudi Med J, 30, 1208-12.

Sharme P, Pattanshetty SM (2018). Astudy on risk factors of cervical caner among patients attending tertiary care hospital: A case control study . $C E G H, \mathbf{6}, 83-7$.

Velenciuc N, Velenciuc I, Luncă S (2009). Considering risk factors and prevention in uterine cervical cancer. Rev Med Chir Soc Med Nat Iasi, 113, 478-81.

Ventola CL (2014). Social media and health care professionals: benefits, risks, and best practices. $P T, \mathbf{3 9}, 491-9,520$.

Von Muhlen M, Ohno-Machado L (2012). Reviewing social media use by clinicians. J Am Med Inform Assoc, 19, 777-81.

Were E, Nyaberi Z, Buziba N (2011). Perceptions of risk and barriers to cervical cancer screening at Moi Teaching and Referral Hospital (MTRH), Eldoret, Kenya. Afr Health Sci, 11, 58-64.

Wong LP, Wong YL, Low WY, Khoo EM, Shuib R (2008). Cervical cancer screening attitudes and beliefs of Malaysian women who have never had a pap smear: A qualitative study. IJBM, 15, 289-92.

World Health Organization (2008). Cervical cancer, human papillomavirus (HPV) and HPV vaccines: Key points for policy-makers and health professionals. WHO Press, 2008. World Health Organization, 20 Avenue Appia, 1211 Geneva 27, Switzerland.

World Health Organization (2013). WHO Guidance Note: Comprehensive Cervical Cancer Prevention and Control. A Healthier Future for Girls and Women. Geneva, Switzerland: World Health Organization. Available from: http://apps.who. int/iris/bitstream/10665/78128/3/9789241505147_eng.pdf. Accessed August, 23, 2018.

This work is licensed under a Creative Commons AttributionNon Commercial 4.0 International License. 